\title{
Variasi Ukuran Puli Terhadap Produksi Hasil Alat Penumbuk Jengkol
}

\author{
Syawaldi \\ Dosen Program Studi Teknik Mesin, Fakultas Teknik \\ Universitas Islam Riau \\ E-mail : syawaldi_a.empat@yahoo.co.id
}

\begin{abstract}
Abstrak
Penelitian ini bertujuan untuk memproduksi emping jengkol berupa kapasitas dan kualitas dalam memproduksi emping jengkol dengan mesin penumbuk emping jengkol yang memvariasikan diameter puli yang berbeda-beda dengan variasi puli ukurans berdiameter 3 inchi, 4 inchi, 5 inchi, dan puli penggerak berdiameter 1,5 inchi. Hasil dari penelitian didapat daya motor penggerak adalah 1/4 HP,kecepatan tumbukan rata-rata mesin yang menggunakan variasi puli penggerak diameter 1,5 inchi dengan puli yang digerakan berdiameter 3 inchi adalah 0,36 cm/s dengan waktu rata-rata tumbukan sebesar 10,65 detik,dan kapasitas produksi emping sebesar 333 emping/jam, sedangkan untuk varasi puli penggerak diameter 1,5 inchi dengan puli yang di gerakan diameter 4 inchi didapat kecepatan rata-rata tumbukan sebesar $0,27 \mathrm{~cm} / \mathrm{s}$ dengan waktu rata-rata yang dibutuhkan mesin untuk menumbuk satu buah emping adalah sebesar 14,17 detik, dan kapasitas produksi emping sebesar 257 emping/jam, dan untuk hasil penelitian menggunakan mesin penumbuk variasi puli penggeraka diameter 1,5 inchi dengan puli yang di gerakan diameter 5 inchi didapatkan kecepatan rata-rata tumbukan sebesar $0,16 \mathrm{~cm} / \mathrm{s}$ dengan waktu rata-rata tumbukan sebesar 23,91 detik, dengan kapasitas produksi emping sebesar 156 emping/jam. Dari penelitian yang telah dilakukan diperoleh hasil produksi yang baik dari ukuran puli 3 inchi dengan kecepatan rata-rata tumbukan sebesar 0,36 cm/s, dengan kapasitas 333 emping/jam.
\end{abstract}

Kata kunci : Mesin penumbuk, Penelitian, Variasi puli, Hasil penelitian

\section{Pendahuluan}

Dalam dimensi baru dan persaingan global, laju perkembangan teknologi semakin pesat dan diiringi dengan persaingan indusrti yang semakin tajam. Perkembangan teknologi telah disadari mampu memberikan keuntungan ekonomi, sehingga banyak orang berusaha untuk mengembangkan potensinya untuk menyerap, menguasai, dan mengadakan teknologi.

Salah satu inovasi teknologi tepat guna (ITTG) adalah mesin penumbuk jengkol dimana mesin penumbuk yang memanfaatkan listrik sebagai sumber energi dan motor listrik sebagai mesin penggerak mampu membantu masyarakat dalam pembuatan emping jengkol dengan cepat. Dibanding dengan cara manual pembuatan emping jengkol membutuhkan waktu yang banyak hasilnya sedikit, dengan manual membutuhkan energy yang relatih besar, sehingga menyebabkan tangan dapat pegal karena menumbuk dan pinggang terasa sakit karena duduk terlalu lama.

Dari data yang didapat dari masyarakat Sebelumnya masyarakat mengolah jengkol menjadi emping dengan cara manual dengan menggunakan tangan dan ditumbuk menggunakan batu, cara kerja seperti ini yang menjadi masalah bagi masyarakat, karena dalam proses pengerjaan banyak memakai waktu dan emping yang dihasilkan juga tidak terlalu banyak, 1 jam penumbukan hanya menumbuk lebih kurang 100 emping jengkol dan itu tergantung kemahiran yang menumbuk.

Berdasarkan permasalahan yang dihadapi masyarakat maka direalisasikan mesin penumbuk emping jengkol dalam membantu masyarakat dan juga untuk meningkatkan kualitas dan kapasitas dari produk emping jengkol tersebut. 


\section{Methodologi}

Langkah - langkah yang dilakukan dalam penelitian ini dapat dilihat pada gambar 1 , sebagai berikut :



Gambar 1. Diagram Alir Penelitian

Berdasarkan gambar Flow Chart, dapat dijelaskan bahwa dalam penelitian terdapat tahaptahap yang dilakukan guna hasil yang didapatkan dalam pegujian ini tepat sasaran dan sesuai yang diharapkan. Antara lain :

a) Survey

Pengambilan data-data penunjang dalam pembuatan mesin sesuai kebutuhan masyarakat, akan sangat bermanfaat guna terciptanya mesin teknologi terbaru yang mengedepankan kebutuhan masyarakat.

b) Persiapan alat dan bahan

Alat yang di persiapkan yaitu mesin penumbuk emping jengkol dan bahan jengkol,serta peralatan pengujian,seperti jangka sorong,stopwatch

c) Proses tumbukan secara manual
Dilakukan untuk mendapatkan kapasitas pembanding.

d) Pengujian Kecepatan tumbukan rata-rata dan waktu tumbukan rata-rata. Dilakukan dengan menggunakan mesin penumbuk emping jengkol yang akan menggunakan variasi perbandingan puli.

\subsection{Instalasi Pengujian}

Skema alat uji penumbuk emping jengkol dapat dilihat pada gambar 2.2 terdiri dari 4 komponen utama yaitu :

1. Rangka

2. Mesin listrik

3. Transmisi sabuk dan puli

4. Poros engkol dan penumbuk

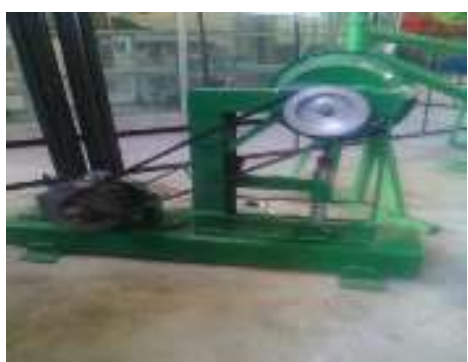

Gambar 2. Skema mesin penumbuk emping jengkol.

\subsection{Proses Kerja Mesin Penumbuk}

Mesin penumbuk emping jengkol digerakkan oleh motor listrik 1/4HP dengan listrik sumber energinya yang akan meneruskan putaran melalui pulli dan sabuk ke poros engkol dan poros engkol akan mengubah gerak rotasi menjadi gerak translasi perubahan gerakan inilah di menyebabkan mesin ini bisa menumbuk. kecepatan tumbukan yang dihasilkan oleh mesin penumbuk emping jengkol tergantung dari besarnya output dari motor listrik dan transmisi pulli dan sabuk.

\subsection{Alat dan Bahan Pengujian \\ $>$ Alat \\ - Mesin penumbuk \\ - Jangka sorong \\ - Stopwatch \\ Bahan \\ - Jengkol. \\ - Plastik.}

\subsection{Prosedur Pengujian}

Pada pengujian dengan mesin penumbuk emping jengkol dilakukan tiga kali pengujian yaitu dengan puli poros diameter 3 inchi , 4 inchi dan puli poros diameter 5 inchi, masing masing dilakukan dalam lima kali pengujian. Proses pengujian dilakukan sebagai berikut: 
1. Persiapan bahan jengkol.

Jengkol yang di jadikan untuk emping harus yang tua agar jengkol tidak pecah saat di tumbuk, jengkol yang telah di belah menjadi dua direndam lebih dari 15 menit kemudian digoreng dan direndam kembali.

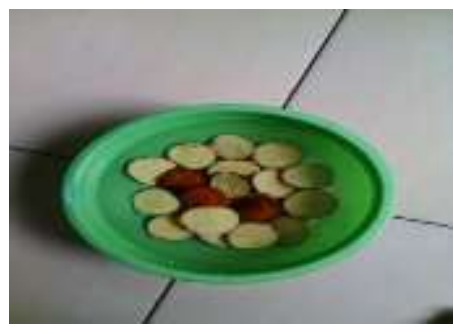

Gambar 3. Bahan Jengkol

2. Masukan satu belah jengkol kedalam plastik yang sudah disiapkan sebelumnya jengkol di timbang dengan neraca pegas dan diukur diameter dan ketebalannya dengan jangka sorong.

3. Pasang puli ukuran 3 inchi pada poros engkol

4. Hidupkan mesin penumbuk

5. Lakukan penumbukan dan catat waktu yang di butuhkan dalam menyelesaikan satu buah emping jengkol.

Setelah semua prosedur pengujian dilakukan dan didapatkan kapasitas tumbukan dengan menggunakan Diameter puli 3 inchi,kemudian lanjutkan dengan Diameter puli 4 dan 5 inchi.

\section{Hasil dan Pembahasan}

\subsection{Menentukan Kecepatan Putaran Puli $\left(n_{2}\right)$}

Untuk menghitung kecepatan putaran puli yang digerakan menggunakan rumus berikut :

$$
n_{2}=n_{1} x \frac{d_{1}}{d_{2}}(r p m)
$$

Dimana :

$n_{1}=$ Putaran motor penggerak $(\mathrm{rpm})=1430 \mathrm{rpm}$

$d_{1}=$ Diameter puli pengerak $(\mathrm{mm})$, dirancang $=$ 1,5 inchi $=38,1 \mathrm{~mm}$,

$d_{2}=$ Diameter puli yang digerakan (mm), direncanakan $=5$ inchi $=127 \mathrm{~mm}$

Maka :

$$
\begin{aligned}
& n_{2}=1430 \times \frac{38,1}{127} \\
& n_{2}=429 \mathrm{rpm}
\end{aligned}
$$

maka kecepatan putaran untuk puli diameter 5 inchi adalah $429 \mathrm{rpm}$, sedangkan untuk kecepatan putaran puli diameter 3 dan 4 inchi dapat dilihat dari tabel 1.

Tabel 1.

Hasil Perhitungan Kecepatan Puli

\begin{tabular}{ccccc}
\hline No & $\begin{array}{c}\text { Diameter } \\
\text { puli }\end{array}$ & $\begin{array}{c}\mathbf{D}_{\mathbf{1}} / \mathbf{D}_{2} \\
(\mathbf{m m})\end{array}$ & $\begin{array}{c}\mathbf{n}_{\mathbf{1}} \\
(\mathbf{r p m})\end{array}$ & $\begin{array}{c}\mathbf{n}_{2} \\
(\mathbf{r p m})\end{array}$ \\
\hline 1 & 3 inchi & $83,1 / 76,2$ & 1430 & 715 \\
2 & 4 inchi & $83,1 / 101,6$ & 1430 & 536,25 \\
3 & 5 inchi & $83,1 / 127$ & 1430 & 429 \\
\hline
\end{tabular}

\subsection{Menentukan Panjang Keliling Sabuk}

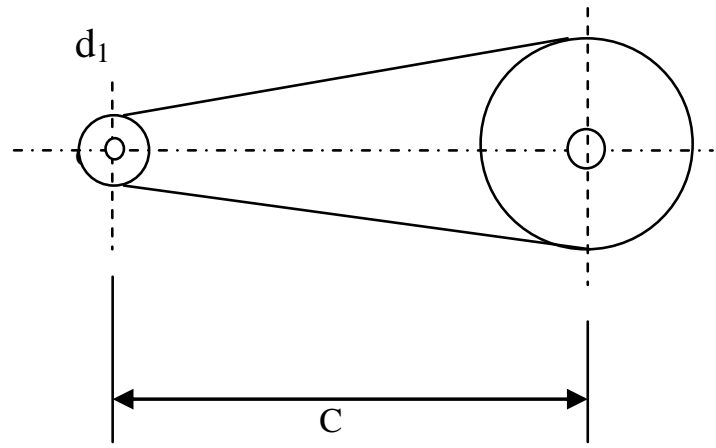

Gambar 4. Perhitungan panjang keliling poros

Keterangan gambar:

$\mathrm{C}=$ Jarak antara kedua sumbu puli $(\mathrm{mm})$

$\mathrm{d}_{1}=$ Diameter puli penggerak $(\mathrm{mm})$

$\mathrm{d}_{2}=$ Diameter puli yang digerakan $(\mathrm{mm})$

Panjang keliling sabuk dapat dihitung dengan menggunakan rumus sebagai berikut :

$$
\mathrm{L}=2 \mathrm{C}+\frac{\pi}{2}\left(\mathrm{~d}_{1}+\mathrm{d}_{2}\right)+\frac{1}{4 . C}\left(\mathrm{~d}_{2}-\mathrm{d}_{1}\right)^{2},(\mathrm{~mm})
$$

Tabel 2.

Hasil perhitungan menentukan panjang keliling sabuk

\begin{tabular}{ccccc}
\hline No & $\begin{array}{c}\text { Diameter } \\
\text { puli }\end{array}$ & $\begin{array}{c}\mathbf{d}_{\mathbf{1}} / \mathbf{d}_{\mathbf{2}} \\
(\mathbf{m m})\end{array}$ & $\begin{array}{c}\mathbf{C} \\
(\mathbf{m m})\end{array}$ & $\begin{array}{c}\mathbf{L} \\
(\mathbf{m m})\end{array}$ \\
\hline 1 & 3 inchi & $83,1 / 76,2$ & 340 & 860,5 \\
2 & 4 inchi & $83,1 / 101,6$ & 340 & 927,5 \\
3 & 5 inchi & $83,1 / 127$ & 340 & 945 \\
\hline
\end{tabular}

\subsection{Menentukan Kecepatan Titik B pada} Mekanisme Poros Engkol

Untuk menentukan kecepatan titik B pada mekanisme poros engkol akan menggunakan perhitungan kecepatan dengan menggunakan metode grafis.Dari data poros engkol diketahui : 
Panjang A. $\mathrm{O}_{12}=30 \mathrm{~mm}$ Panjang A.B $=82 \mathrm{~mm}$



Gambar 5. Diagram kinematika

1. Kecepatan titik $A$ dan $B$ dengan menggunakan puli 3 inchi

> Kecepatan titik A dapat dihitung dengan persamaan berikut:

$V_{A}=O_{12} A \times n$

Dimana:

$\mathrm{V}_{\mathrm{A}}=$ Kecepatan pada titik A $(\mathrm{m} / \mathrm{s})$

$\mathrm{O}_{12} \mathrm{~A}=$ Jari-jari titik A terhadap pusat rotasi $(\mathrm{m})$

$\mathrm{n} \quad=$ kecepatan batang hubung $2(\mathrm{rpm})$ diketahui:

$\mathrm{O}_{12} \mathrm{~A}=0,03 \mathrm{~m}$

$\mathrm{n}=715 \mathrm{rpm}=11,92 \mathrm{rps}$

Maka:

$$
\begin{aligned}
V_{A} & =0,03 \times 11,92 \\
& =0,36 \mathrm{~m} / \mathrm{s} \\
& =36 \mathrm{~cm} / \mathrm{s}
\end{aligned}
$$

Kecepatan titik B dapat di tentukan dengan persamaan kecepatan relatif berikut: $V_{B}=V_{A} \rightarrow V_{B / A}$

Dimana :

$\mathrm{V}_{\mathrm{B}}=$ Arah nya diketahui

$\mathrm{V}_{\mathrm{A}}=$ Arah dan besar vektor di ketahui

$\mathrm{V}_{\mathrm{B} / \mathrm{A}}=$ Tegak lurus $\mathrm{AB}$

Poligon kecepatan dibuat sebagai berikut:

Menggambarkan vektor kecepatan yang sudah diketahui arah dan besar nya, yaitu $\mathrm{V}_{\mathrm{A}}$ dengan skala $1 \mathrm{~cm}: 7 \mathrm{~cm} / \mathrm{s}$ maka panjang vektor $\mathrm{V}_{\mathrm{A}}$ adalah :

$V_{A}=36 \mathrm{~cm} / \mathrm{s} \times \frac{1 \mathrm{~cm}}{7 \mathrm{~cm} / \mathrm{s}}=5,1 \mathrm{~cm}$



Gambar 6. Poligon kecepatan

Dari gambar poligon kecepatan didapat panjang vektor $\mathrm{V}_{\mathrm{B}}=6 \mathrm{~cm}$ Maka kecepatan pada titik $B$ adalah

$$
\begin{aligned}
V_{B} & =6 \mathrm{~cm} \times \text { skala gambar } \\
& =6 \mathrm{~cm} \times \frac{7 \mathrm{~cm} / \mathrm{s}}{1 \mathrm{~cm}} \\
& =42 \mathrm{~cm} / \mathrm{s} \\
& =0,42 \mathrm{~m} / \mathrm{s}
\end{aligned}
$$

Untuk kecepatan titik A dan B dengan menggunakan puli 4 dan 5 inchi dapat dilihat pada tabel 3 .

Tabel 3.

Hasil perhitungan mencari kecepatan titik A dan B pada mekanisme poros engkol.

\begin{tabular}{llll}
\hline No & Diameter puli & $\begin{array}{l}\mathrm{V}_{\mathrm{A}} \\
(\mathrm{m} / \mathrm{s})\end{array}$ & $\begin{array}{l}\mathrm{V}_{\mathrm{B}} \\
(\mathrm{m} / \mathrm{s})\end{array}$ \\
\hline 1 & Puli 3 inchi & 0,36 & 0,42 \\
2 & Puli 4 inchi & 0,26 & 0,3 \\
3 & Puli 5 inchi & 0,21 & 0,24 \\
\hline
\end{tabular}

\subsection{Analisa pengaruh diameter puli terhadap hasil} produksi mesin penumbuk emping jengkol.

Untuk mengetahui pengaruh dari diameter puli poros engkol maka dilakukanlah pengujian, dengan membandingkan tiga buah puli dengan ukuran diameter 3 inchi, 4 inchi dan 5 inchi, dari

\begin{tabular}{|c|c|c|c|c|c|c|c|}
\hline \multirow{3}{*}{ No } & \multicolumn{4}{|c|}{ Jengkol } & \multirow{3}{*}{$\mathrm{L}$} & \multirow{3}{*}{$\mathrm{t}$} & \multirow{3}{*}{$\mathrm{v}$} \\
\hline & \multicolumn{2}{|c|}{ Sebelum } & \multicolumn{2}{|c|}{ Sesudah } & & & \\
\hline & Dia & $\mathrm{Tbl}$ & Dia & Tbl & & & \\
\hline 1 & 38 & 12 & 122 & 1 & 3,8 & 11,54 & 0,33 \\
\hline 2 & 38 & 12 & 109 & 1 & 3,8 & 09,78 & 0,39 \\
\hline 3 & 38 & 12 & 118 & 1 & 3,8 & 10,79 & 0,35 \\
\hline 4 & 38 & 12 & 105 & 1 & 3,8 & 09,80 & 0,39 \\
\hline 5 & 38 & 12 & 121 & 1 & 3,8 & 11,30 & 0,34 \\
\hline $\mathrm{rt}$ & 38 & 12 & 115 & 1 & 3,8 & 10,65 & 0,39 \\
\hline
\end{tabular}
hasil pengujian dapat diketahui berapa kecepatan tumbukan dan waktu yang di perlukan dalam satu kali proses tumbukan.

Tabel 4.

Data kecepatan tumbukan rata-rata pada puli 3 inchi dengan kecepatan putaran $715 \mathrm{rpm}$ 
Keterangan :

$$
\begin{aligned}
\mathrm{L} & =\text { jarak tumbukan }(\mathrm{cm}) \\
\mathrm{t} & =\text { waktu dalam penumbukan }(\mathrm{s}) \\
\mathrm{v} & =\text { kecepatan tumbukan }(\mathrm{cm} / \mathrm{s})
\end{aligned}
$$

\subsection{Hasil pengujian secara manual dan mesin penumbuk emping jengkol}

Untuk membandingkan kapasitas dan kualitas produksi emping jengkol dilakukan pengujian secara manual dan mesin penumbuk emping jengkol, untuk hasil pengujian dapat dilihat pada tabel 5 .

\begin{tabular}{|c|c|c|c|}
\hline No & Proses Tumbuk & $\begin{array}{c}\text { Kapasitas } \\
\text { (emping/ } \\
\text { jam) }\end{array}$ & Kualitas tumbukar \\
\hline 1 & Secara Manual & 96 & $\begin{array}{l}\text { - Diameter seragam } \\
\text { - Ketebalan hampir seragam } \\
\text { - Permukaan tidak datar }\end{array}$ \\
\hline 2 & $\begin{array}{l}\text { Mesin } \\
\text { penumbuk } \\
\text { dengan puli } \\
3 \text { inchi } \\
\end{array}$ & 333 & $\begin{array}{ll} & \text { Diameter hampir seragam } \\
\text { - } & \text { Ketebalan seragam } \\
\text { - } & \text { Permukaan emping datar }\end{array}$ \\
\hline 3 & $\begin{array}{l}\text { Mesin } \\
\text { penumbuk } \\
\text { Dengan puli } \\
4 \text { inchi } \\
\end{array}$ & 257 & $\begin{array}{l}\text { - } \text { Diameter hampir seragam } \\
\text { - } \text { Ketebalan hampir seragam } \\
\text { - } \text { Permukaan emping datar }\end{array}$ \\
\hline 4 & $\begin{array}{l}\text { Mesin } \\
\text { penumbuk } \\
\text { Dengan puli } \\
5 \text { inchi } \\
\end{array}$ & $\begin{array}{l}156 \\
\text { emping/ja } \\
\mathrm{m}\end{array}$ & $\begin{array}{ll}- & \text { Diameter tidak seragam } \\
\text { - } & \text { Ketebalan hapir seragam } \\
\text { - } & \text { Permukaan emping datar }\end{array}$ \\
\hline
\end{tabular}

Tabel 5.

Hasil pengujian secara manual dan mesin penumbuk

\section{Hasil dan Pembahasan}

3.1. Kapasitas produksi mesin penumbuk emping jengkol

Dari hasil pengujian yang dapat dilihat pada tabel 5 diatas diperoleh perbandingan hasil produksi secara manual dan mesin penumbuk emping jengkol dari perbandingan diameter puli sebagai berikut:

Pada mesin penumbuk emping jengkol dengan menggunakan puli berdiameter 3 inchi dengan kecepatan putaran 715 rpm kapasitas produksi 333 emping/jam lebih tinggi dibanding dengan tumbukan secara manual dengan kenaikan kapasitas produksi sebesar 246,8 \%, sedangkan pada puli diameter 4 inchi dan 5 inchi dapat dilihat kenaikan kapasitas produksi pada tabel 6 dibawah ini :

Tabel 6.

Produksi mesin penumbuk setiap puli VS pengerjaan manual, dimana kapasitas produksi penumbukan secara manual sebesar 96 emping/jam.

\begin{tabular}{cccc}
\hline No & $\begin{array}{c}\text { Mesin penumbuk } \\
\text { Dengan menggunakan } \\
\text { Puli }\end{array}$ & $\begin{array}{c}\text { Kapasitas } \\
\text { (emping/jam) }\end{array}$ & $\begin{array}{c}\text { Kenaikan } \\
\text { kapasitas } \\
(\%)\end{array}$ \\
\hline 1 & Puli 3 inchi & 333 & $246,8 \%$ \\
2 & Puli 4 inchi & 257 & $167,7 \%$ \\
3 & Puli 5 inchi & 156 & $62,5 \%$ \\
\hline
\end{tabular}

1. Pembuatan emping jengkol dengan mesin penumbuk emping jengkol menggunakan puli 3 inchi mempunyai nilai efesiensi yang tinggi sebesar 184,3 \% jika dibandingkan dengan penggunaan puli 5 inchi dan 79,1 \% dibandingkan dengan penggunaan puli 4 inchi.

2. Penumbukan emping jengkol secara manual tidak kontinyu disebabkan faktor kelelahan manusia, dibanding dengan mesin penumbuk yang menumbuk secara kontinyu dengan kecepatan tumbukan yang cepat.

3. Kualitas tumbukan menggunakan puli 3 inchi lebih baik dan menghasilkan produksi emping tebih banyak di bandingkan penggunaan puli 4 inchi dan 5 inchi, pada penggunaan puli 5 inchi terdapat kecepatan tumbukan yang tidak konstan karena putaran yang di hasilkan kecil dan tekanan juga kecil sehingga saat penumbukan terjadi kesendatan.

\section{Simpulan}

\subsection{Simpulan}

Dari hasil perhitungan dan analisa mesin penumbuk emping jengkol maka dapat diambil kesimpulan sebagai berikut :

L. Daya motor penggerak yaitu $1 / 4 \mathrm{HP}$.

2. Dari perhitungan di dapatkan kecepatan putaran puli 3 inchi $715 \mathrm{rpm}$, puli 4 inchi 536,25 rpm, dan puli 5 inchi $429 \mathrm{rpm}$.

3. Kecepatan titik A dan B pada mekanisme poros engkol untuk masing-masing puli yaitu

- Puli 3 inchi $\mathrm{V}_{\mathrm{A}}: 0,3 \mathrm{~m} / \mathrm{s}$ dan $\mathrm{V}_{\mathrm{B}}: 0,42 \mathrm{~m} / \mathrm{s}$

- Puli 4 inchi VA : 0,268 m/s dan VB : 0,30 $\mathrm{m} / \mathrm{s}$

- Puli 5 inchi VA : 0,214 m/s dan VB : 0,24 $\mathrm{m} / \mathrm{s}$

4. Kapasitas mesin penumbuk menggunakan puli berdiameter 3 inchi dengan putaran 715 rpm sebesar 333 emping/jam, dengan kualitas produksi bagus dilihat dari segi ketebalan dan permukaan emping yang merata.

5. Kapasitas mesin penumbuk menggunakan puli berdiameter 4 inchi dengan putaran 536,25 rpm sebesar 257 emping/jam, dengan kualitas produksi juga bagus dilihat dari segi permukaan emping yang rata.

6. Kapasitas mesin penumbuk menggunakan puli berdiameter 5 inchi dengan kecepatan putaran $429 \mathrm{rpm}$ sebesar 156 emping/jam.

7. Dari analisa yang sudah dilakukan maka dapat diambil kesimpulan bahwa mesin penumbuk emping jengkol yang dirancang 
menggunakan puli 3 inchi lebih bagus di bandingkan dari rancangan menggunakan puli berdiameter 4 dan 5 inchi, di lihat dari segi kapasitas dan kualitas produksi emping yang di hasilkan.

8. Dengan mesin penumbuk menggunakan diameter puli 3 inchi kenaikan kapasitas produksi emping sangat besar dibanding dengan penggunaan diameter puli 4 dan 5 inchi, Yaitu sebesar 246,8 \% dari pengerjaan maual.

9. Pembuatan emping jengkol dengan mesin penumbuk emping jengkol menggunakan puli Diameter 3 inchi mempunyai nilai efesiensi yang tinggi sebesar 184,3 \% jika dibandingkan dengan penggunaan puli Diameter 5 inchi dan 79,1 \% dibandingkan dengan penggunaan puli Diameter 4 inchi.

\subsection{Saran}

Dalam penumbukan emping jengkol disarankan jengkol yang di gunakan yaitu yang sudah tua agar hasil nya lebih baik dan tidak pecah saat penumbukan, dan saat mengoperasikan mesin penumbuk emping jengkol supaya memakai pengaman telinga karna bunyi yang di timbulkan mesin saat menumbuk emping sangan berisik. Dalam perencanaan mekanisme mesin penumbuk emping jengkol ini perlu adanya saran agar alat ini dapat lebih dikembangkan lagi.

\section{Daftar Pustaka}

1. P.Beer Ferdinan, E. Jr. Johonson Russel. 1983. "Mekanika Untuk Insinyur". Penerbit Erlangga. Jakarta.

2. Holowenko, A. R. 1993. "Dinamika Permesinan". Penerbit Erlangga, Jakarta.

3. Sularso, Kiyokatsu Suga. 2008. "Dasar perencanaan dan pemilihan elemen mesin". Pradnya Pramita, Jakarta.

4. Liong,A.Pugerri Toni, "Diktat kuliah Lelah dalam perancangan", Jakarta 1999.

5. L. Mott, Robert. 2009. "elemen-elemen mesin dalam perancangan mekanis Buku 2". Penerbit andi.

6. Rohim Taufik. 1993. "Teori dan proses permesinan teknik mesin.ITB. Bandung.

7. Suhariyanto. 2006. "Elemen mesin I". Surabaya. Institut Teknologi Sepuluh Nopember. Surabaya. 